\title{
What is the Clinical Impact of an Analytic Tool for Predicting the Fall Risk in Inpatients on Nursing Sensitive Outcomes?
}

Insook Cho ( $\nabla$ insook.cho@inha.ac.kr)

Inha University College of Medicine https://orcid.org/0000-0002-5152-9567

Insun Jin

National Health Insurance Corporation Ilsan Hospital

Hyunchul Park

Konkuk University

Patricia C. Dykes

Brigham and Women's Hospital

\section{Research}

Keywords: Inpatient falls, Risk prediction, Analytic tool, Nursing sensitive outcomes, Process outcomes, Double-blind experiment

Posted Date: August 17th, 2020

DOl: https://doi.org/10.21203/rs.3.rs-56042/v1

License: () (1) This work is licensed under a Creative Commons Attribution 4.0 International License. Read Full License 


\section{Abstract \\ Objectives}

Patient falls remain a common cause of harm in acute-care hospitals worldwide. The purpose of this study was to explore whether an electronic analytic tool for predicting fall risk can improve clinical outcomes, including reducing inpatient falls in an acute-care setting.

\section{Methods}

We performed a double-blind experimental study that included a nonequivalent control group in 12 medical-surgical nursing units at a public hospital between May 2017 and April 2019. The intervention was the provision of risk prediction information generated by an analytic tool using nursing data obtained from the hospital's electronic health record system. The primary outcome was the rate of falls, and secondary outcomes included fall-related injuries, the daily frequencies of nursing activities provided to patients and predefined process indicators.

\section{Results}

During the study there were 42,476 admissions, while 707 falls and 134 fall injuries occurred. The fall rate differed significantly between the two groups ( 1.79 vs. $2.11, t=2.13, P=0.0383)$, considering the interrupted time series analysis, a significant absolute reduction of $29.73 \%$ was noted in the intervention group ( $z$ $=-2.06, P=0.0391)$, versus a $16.58 \%$ reduction in the control group $(z=-1.28, P=0.2000)$. The injury rates were not significantly different $(0.42$ vs. $0.31, t=$ $-1.54, P=0.1306)$. Patient-level-adjusted logistic regression showed a significant group effect on falls. Process outcomes on universal precautions were significantly better at the control units from baseline, while risk-targeted interventions increased slowly and more in the intervention group over time.

\section{Conclusion}

The introduction of an electronic analytic tool demonstrated the potential to contribute to improvement of patient outcomes, leading to positive, qualitative changes in process outcomes. Multihospital studies and combining this type of tool with efficient intervention strategies are needed to reduce both falls and fall-related injuries.

\section{Trial registration:}

Korean National Research Institute of Health, KCT0005286, Registered 4 August 2020 - Retrospectively registered, https://cris.nih.go.kr/cris/en/search/search_result_st01.jsp?seq=16984

\section{Contributions To The Literature}

\section{What is already known on this topic}

$\lambda$ Despite the availability of a considerable body of literature on fall prevention and reduction, inpatient falls remain a difficult, complex, and common problem requiring a great deal of nurses' time, attention, and effort in practice

- Several heuristic risk assessment tools have used widely, but none of them were adequately replicated in the relevant setting.

- With recent rapid expansion of health care predictive analytic application along with growing availability of electronic health record data, patient-level electronic analytic tools for predicting fall risk were developed.

\section{What this study adds}

- Our study suggests that a patient-level electronic analytic tool has the potential to contribute to reducing rates of falls.

- Our study suggests that the continuous measurement and analysis of process outcomes were informative to infer the effect of interventions to patient outcomes as well as interpret the effect of confounding.

\section{Introduction}

Inpatient falls are a preventable adverse event that are among the top-10 sentinel events in hospitals. Up to 1 million fall events occur annually in the US and cost an additional $\$ 7,900-\$ 17,099$ (2019 USD) $(1,2)$. A review of currently published studies $(3-5)$ revealed that $400 \sim 700$ such events occur annually in Korean tertiary academic hospitals.

Despite the availability of a considerable body of literature on fall prevention and reduction, falls remain a difficult, complex, and common problem requiring a great deal of nurses time, attention, and effort to complete fall prevention in practice $(6,7)$. One-third of inpatient falls are known to be preventable, but the inability to accurately estimate the risk of falling is a major hurdle to preventing falls $(8,9)$. Several risk assessment tools developed with heuristic approach have used widely to estimate fall risk in acute care settings. However, none of them were adequately replicated in the relevant setting, and clinical guidelines and researchers commonly recommend multifactorial risk assessment, rather than use of one risk assessment tool (9-12). Another problem is little variations 
and differences of nursing interventions provided to patient at-risk and not at-risk days. According to clinical observation, limited number of universal precautions were repeated depending on the scores of a risk assessment tool, rather than risk-targeted intervention.

Given the increased adoption of electronic health record (EHR) systems over the past decade, it may be possible to use of nursing assessment data which routinely captured through EHR systems to predict inpatient falls (13). In our previous work, a predictive analytic tool designed with probability technique performed better at discriminating at-risk and no-risk patients than did the existing fall risk assessment tools alone (14). As a sort of health care predictive analytics, nursing predictive analytics can be defined to include information regarding the likelihood of a future patient event through risk prediction models that incorporate multiple predictor variables automatically from one or more sources of nursing-related data beyond what can be simply calculated by most nurses. Several studies have investigated variable selection, model development, and validation in nursing for predictive analytics (5, 15-20). However, only a few studies have analyzed predictive models in real-world settings and explored the influence or relationships with nursing sensitive outcomes. Several studies $(15,16,18,19)$ have explored rescue failures, such as clinical deterioration alerts and the early detection of sepsis, and prediction of adverse event such as pressure ulcers. These studies produced mixed results. One (15) concluded that simple laboratory and vital-sign criteria were insufficient for improving outcomes in sepsis. Other studies $(17,21)$ reported positive changes in outcomes. However, little have known about the clinical feasibility, values and nurses' responses on nursing analytic approaches and tools.

Recent growing availability of EHR data has great opportunities to rapid expansion of health care predictive analytic application (22). This study applied predictive analytics to inpatient falls and explored its relationship with patient and process outcomes in a real-world setting. This study hypothesized that knowledge of fall events that are likely to occur within 24 hours based on data routinely captured in EHRs would enable nurses to conduct multifactorial assessment and provide risk-targeted interventions to at-risk patients.

\section{Background}

\subsection{Development of Inpatient Fall Risk Prediction Model}

We reported the methods and results of the development of a risk prediction model in detail previously (14), but will introduce it briefly here. To identify concepts of fall risk factors and prevention care, two international practice guidelines $(9,12)$ and two implementation guidelines $(23,24)$ on preventing inpatient falls were used. Two standard vocabularies, the Logical Observation Identifiers Names and Codes (25) and the International Classification for Nursing Practice ${ }^{\circledR}(25,26)$, were used to represent the concepts in the prediction model, which was then represented with a probabilistic Bayesian network.

Using two study cohorts obtained from two hospitals with different EHR systems and nursing vocabularies, the model was tested. The model concepts were mapped to local data elements of each EHR system and two implementation models were developed for a proof-of-concept approach, followed by cross-sites validation. The EHR data included in the model were demographics, administrative information, medications, patient classifications, the fall-risk-assessment tool, and nursing processes including assessments and interventions. The two implementation models showed error rates of $11.7 \%$ and $4.87 \%$ with $c$ statistics of 0.96 and 0.99 , respectively. The model performed $27 \%$ and $34 \%$ better than the existing Hendrich II (27) and STRATIFY (St. Thomas' Risk Assessment Tool in Falling Elderly Inpatient) (28) tools.

\subsection{IN@SIGHT system}

The validation-site model was implemented as the IN@SIGHT (Intelligent Nursing @ Safety Improvement Guide of Health Technology) system version 1.0 at a public 900-bed hospital located in the metropolitan area of Seoul (Republic of Korea) that used to the STRATIFY to assess fall risks for all inpatients. The analytic tool was integrated into the locally developed hospital EHR system that had been used for more than 10 years. The tool was deployed in six targeted nursing units on April 5, 2017 and 204 nurses received the patient-level prediction results daily. In this implementation process, the research team engaged with the chief of the nursing department, unit managers, unit champions, personnel of the department of medical informatics, and the patient safety committee. For 3 months before the system deployment, 3 sessions of education for the IN@SIGHT was provided to intervention group, which were followed by peer-to-peer education by unit champions at each unit. The nursing department decided to replace the existing STRATIFY with the analytic tool in this quasi-experimental study. Accordingly, the original model was customized by replacing the six data elements in the STRATIFY with proxy data elements in the EHR. The adjusted model consisted of 40 nodes and 68 links that showed an error rate of $9.3 \%$ and a spherical payoff of 0.92 with a $c$ statistic of 0.87 . Related work processes were redefined and the existing fall-prevention documentation screen of the EHR was modified to facilitate data input (Fig. 1). The readjusted model showed an area under the receiver operating characteristic curve of $88.98 \%$. The hospital decided to deliver the risk information in a dichotomized format with at-risk and no-risk categories at a cutoff point of $15 \%$ preserving high specificity of $89.4 \%$ and sensitivity of $66.1 \%$.

\section{Methods}

\subsection{Study Framework and Objectives}

To guide the study, a conceptual study framework was developed from the nursing role effectiveness model (29). (Fig. 2) This study assumed the precise and up-to-date prediction on fall events within 24 hours will affect rates of falls as well as process outcomes. The STRATIFY has used to classify about $40 \sim 50 \%$ hospital days (HD) into at-risk, while the IN@SIGHT predict about 20\% HD for at-risk days. The rates of falls in the site was around 2 per 1000 HD.

The purpose of this study was to explore the feasibility, values, and nurses' responses on the first version (version 1.0) of IN@SIGHT. The following specific research questions were addressed:

1. Does the patient-level analytic tool influence the quality of nursing care as assessed using outcome indicators? 
2. Does the predictive analytic tool affect nursing activities provided to patients?

3. How does the influence change over time?

\subsection{Study Design and Setting}

The study design was a double-blind experiment involving nonequivalent groups conducted in 12 medical-surgical units of the hospital from May 1,2017 to April 30, 2019 (Fig. 3). The pre-intervention periods were set 16 months before the introduction, which was the maximum time window retrospectively because of the changes of nursing staffing according to government policy. The participating units were paired based on previous rates of falls and patient characteristics as best as we can. However, due to the limited number of units, neurology, geriatric, and surgery units were imbalanced. Patients who meet the following criteria were eligible; at least 18 years of age, and admitted for more than 1 day in departments other than pediatrics, psychiatrics, obstetrics, and emergency care. During the study we surveyed nurses in the intervention group every 6 months to monitor nurse-system interactions, such as their perceptions, knowledge and attitudes about fall prevention tasks, user satisfaction, and experience, which were reported in detail elsewhere (30).

The hospital's ethical committee waived the need to obtain consent from individual patients and nurses, which enabled all patients and nurses in the participating units to be included as study participants (IRB No. NHIMC 2016-08-005).

\subsection{Comparator and Outcome Measures}

Inpatients in the control group received the usual care using the STRATIFY. The modified nursing record screen for fall prevention in the EHR system was introduced to both groups. Hospital policies dictated that the same fall-prevention practices were recommended to both the control and intervention groups.

The primary outcome was the rate of falls per $1000 \mathrm{HD}$. We adopted the falls definition of the National Database of Nursing Quality Indicator outcome metrics of the American Nurses Association (31). A fall injury was considered minor and more levels as determined within 24 hours by the hospital.

The secondary outcomes were the rates of fall injuries and process outcomes. The process outcomes are calculated from nursing activities provided to patients to prevent falls. These activities were categorized into 17 care components based on international guidelines (32). Regarding the process outcomes, the nursing indicators which were previously identified as eMeasurements of inpatient falls were used (33). These process indicators were used to determine whether nurse behaviors can independently affect patient outcomes. Each process indicator measures the proportion of at-risk patients who are given the targeted interventions. For example, all hospitalized patients are expected to be assessed for fall-risk factors within 24 hours of admission, and at-risk patients are expected to receive risk-targeted interventions within 24 hours of risk identification.

\subsection{Data Collection}

As a pre-intervention period, patient outcome data of 16 months before the experiment were collected from the hospital's quality-assurance department to provide a baseline reference for comparison. However, the fall-injury rates before this experiment was not comparable due to differences in criteria used to calculate only severe level injuries as a sentinel event at the hospital. For process indicators, 1-month of data before the experiment were collected as a baseline. During the study period, data on patient demographics and medications, nursing activities, the STRATIFY, and administrative information were collected from the EHR system and falls data from the hospital's quality-assurance department. To monitor and minimize the underreporting rate which was observed in our previous work $(33,34)$, the nursing department conducted education to all units to remind them about the principle of reporting and documentation and provided monthly chart reviews and feedback.

\subsection{Sample Size and Statistical Analysis}

This study hypothesis was that the fall rate will be reduced by $15 \%$ during the 24 -month implementation of the prediction program. We estimated the required sample size conservatively based on previous research (14). The estimation presumed a fall rate in the control group of 2.0 per $1000 \mathrm{HD}$, an average of 15,000 HD per unit over 12 months, and an average 1,700 admissions. The required number of falls in the control group was calculated while assuming a Poisson distribution as $D_{0}=z^{2}(\theta+1) / \theta\left(\log _{e} \theta\right)^{2}(7)$. We applied a rate ratio $(\theta)$ of 0.85 and $z=2.0$. Detecting a rate ratio of 0.85 between groups at the $5 \%$ significant level with a statistical power of $80 \%$ required 610 falls, which corresponded to a 24 -month period for the 12 units.

The participant characteristics were compared using chi-square tests for categorical variables and $t$-tests for continuous variables. $T$-tests to compare rates of falls and fall injuries between the two groups and a longitudinal analysis of cluster-level data were used; generalized least squares (GLS) estimation to examine the association between group and outcomes, and regression with a fixed-effect model using least-squares dummy-variable method. To compare rates of falls pre- and post-intervention periods by group, a cluster-level interrupted time series study with calendar month as the unit of time was performed. This quasi-experimental design accounts for temporal trends while examining the association between introduction of the analytic tool and outcomes; these associations were analyzed using segmented regression analysis (35). We fit negative binomial models; we included 3 variables to measure the relationship of time and the rates of falls: (i) a continuous variable to represent the underlying temporal trends; (ii) a dummy variable for the date after May 1 st, 2017 , to determine the change in rate of falls related to the intervention; and (iii) a continuous time variable beginning on that date, to represent the change in slope. The coefficients of the second and third variables indicated whether the intervention had an immediate or ongoing effect on rate of falls, respectively. For the patient-level analysis, adjusted logistic regression was used. The process indicators were also compared between groups using chi-square test.

\section{Results}

\subsection{Patient Characteristics}


This study involved 42,476 admissions of 40,345 unique patients from 12 units, which corresponded to 362,805 HD at the nursing units across both groups. There were 2,131 patients who were admitted to both an intervention and a control unit at different times (5.02\% of all admissions). The patient characteristics differed significantly between the two groups (Table 1). The control units were characterized by older patients, a longer stay, fewer female patients, more falls, and more patients with a fall history at admission, comorbidity status, and surgical procedures. Regarding the primary diagnosis, about half of the patients in the intervention group had respiratory or digestive disease, or any form of cancer, while control patients had a greater diversity of diagnoses. These significant patient characteristics were used to control the patient-level differences for group effect on rates of falls.

Table 1

Characteristics of patients in the intervention and control groups

\begin{tabular}{|c|c|c|c|}
\hline Variables & $\begin{array}{l}\text { Intervention } \\
(n=24,336)\end{array}$ & $\begin{array}{l}\text { Control } \\
(n=18,140)\end{array}$ & $P$ \\
\hline Age, years & 61.45 (61.23 to 61.67$)$ & $65.30(65.05$ to 65.54$)$ & $<.0001$ \\
\hline Length of stay, days & 7.96 (7.91 to 8.00$)$ & 9.25 (9.13 to 9.37$)$ & $<.0001$ \\
\hline Sex, female & $12,512(51.41)$ & $9,053(49.91)$ & .0021 \\
\hline Fall events & & & $<.0001$ \\
\hline One & $305(1.25)$ & $372(2.05)$ & \\
\hline Two or more & $20(0.08)$ & $10(0.06)$ & \\
\hline Presence of fall history at admission & $2,873(11.88)$ & $4,138(23.58)$ & $<.0001$ \\
\hline Presence of secondary diagnoses & $10,641(43.73)$ & $9,361(51.60)$ & $<.0001$ \\
\hline Presence of surgical procedures & $2,483(10.20)$ & $8,575(47.27)$ & $<.0001$ \\
\hline Primary medical diagnosis & & & $<.0001$ \\
\hline Respiratory or digestive disease & $6,150(25.21)$ & $3,472(19.14)$ & \\
\hline Cancer & $5,990(24.61)$ & 2,382 (13.13) & \\
\hline Symptom or injury & $2,784(11.44)$ & $2,561(14.12)$ & \\
\hline Cardiovascular disease & $995(4.09)$ & $3,096(17.07)$ & \\
\hline Benign tumor & $860(3.53)$ & $211(1.16)$ & \\
\hline Infectious disease & $514(2.11)$ & $388(2.14)$ & \\
\hline Neurologic disease & $182(0.75)$ & $597(3.29)$ & \\
\hline Other ${ }^{+}$ & $6,861(28.19)$ & $5,433(29.95)$ & \\
\hline \multicolumn{4}{|c|}{ Data are $n(\%)$ or mean ( $95 \%$ confidence interval) values } \\
\hline
\end{tabular}

\subsection{Comparison of Primary Outcomes}

Mean rates of falls decreased from 1.92 to 1.79 in the intervention group, while increased from 1.95 to 2.11 in the control group. In the simple $t$-test comparisons of monthly rates, the fall rate was lower in the intervention group (1.79 vs. $2.11, t=2.13, P=0.0383$ ). The longitudinal analysis of nursing-unitlevel data showed no autocorrelation within groups $(P=0.4029)$, while the group effect was significant for the fall rate $(z=-2.10, P=0.0360)$. The fixed-effect model also predicted a significant group effect $(t=2.13, P=0.0383)$. In the interrupted time series analysis for the intervention group, we found a significant decrease of $29.7 \%(95 \% \mathrm{Cl},-1.4 \%,-58.0 \%)$ in odds of rate of falls with introduction of the intervention, followed by a nonsignificant increase in odds of rate of falls of $1.1 \%(95 \% \mathrm{Cl},-0.04 \%, 2.2 \%)$ per month as compared to the underlying time trend. (Table 2$)$; the latter value was not significant $(P=0.059)$. While the control group showed nonsignificant decrease in odds of $16.6 \%(95 \% \mathrm{Cl},-41.9 \%, 8.8 \%)$ as immediate impact, followed by a nonsignificant increase of $1.2 \%$ (95\% Cl, $-0.04 \%, 2.4 \%)$.

Table 2

Results of cluster-level interrupted time series analysis on rates of falls

\begin{tabular}{|llll|}
\hline Group & Rate of change prior to IN@SIGHT & Change in level, introduction of IN@SIGHT & Change in rate post IN@SIGHT \\
\hline Intervention & $0.93(0.78-1.08)$ & $0.70(0.42-0.86)^{*}$ & $1.01(1.00-1.02)$ \\
\hline Control & $1.08(0.94-1.22)$ & $0.83(0.58-1.09)$ & $1.01(1.00-1.02)$ \\
\hline Data are odds $\left(95 \%\right.$ confidence interval) values, ${ }^{*} p<0.05$ & \\
\hline
\end{tabular}

In the patient-level analysis adjusted patient characteristics, the overall group effect was significant (odds ratio $=0.52,95 \% \mathrm{Cl}=0.42$ to $0.65, P<0.0001$ ). The group effect occurred in the time periods other than the first and last 6 months (Table 3). 
Results of patient-level logistic regression by time period

\begin{tabular}{|c|c|c|c|c|}
\hline \multirow[t]{2}{*}{ Variable } & \multicolumn{4}{|l|}{ Time } \\
\hline & $\begin{array}{l}\text { 1st period } \\
(n=10,514)\end{array}$ & $\begin{array}{l}\text { 2nd period } \\
(n=9,849)\end{array}$ & $\begin{array}{l}\text { 3rd period } \\
(n=11,196)\end{array}$ & $\begin{array}{l}\text { 4th period } \\
(n=10,815)\end{array}$ \\
\hline \multirow[t]{2}{*}{ Group of intervention } & 0.66 & $0.25^{* *}$ & $0.36^{* *}$ & 1.07 \\
\hline & (0.44 to 1.00$)$ & (0.12 to 0.53$)$ & $(0.21$ to 0.61$)$ & (0.82 to 1.59$)$ \\
\hline \multirow[t]{2}{*}{ Age } & $1.06^{* *}$ & 1.04 * & $1.03^{* *}$ & 1.01 \\
\hline & (1.04 to 1.08$)$ & (1.02 to 1.06$)$ & (1.01 to 1.04$)$ & (0.99 to 1.02$)$ \\
\hline \multirow[t]{2}{*}{ Length of stay } & $1.05^{* *}$ & $1.07^{* *}$ & $1.03^{* *}$ & $1.04^{* *}$ \\
\hline & (1.03 to 1.07$)$ & (1.04 to 1.11$)$ & (1.02 to 1.05$)$ & (1.03 to 1.05$)$ \\
\hline \multirow[t]{2}{*}{ Female sex } & 0.77 & 0.93 & 0.70 & 0.71 \\
\hline & (0.50 to 1.18$)$ & (0.55 to 1.57$)$ & (0.49 to 1.01$)$ & (0.49 to 1.05$)$ \\
\hline \multirow[t]{2}{*}{ Presence of fall history at admission } & 2.21 * & 1.30 & $3.44^{* *}$ & $82.83^{\star *}$ \\
\hline & $(1.36$ to 3.60$)$ & (0.72 to 2.36$)$ & $(2.27$ to 5.22$)$ & (42.62 to 160.98$)$ \\
\hline \multirow[t]{2}{*}{ Number of secondary diagnoses } & 1.04 & 1.14 & 1.20 ** & 1.01 \\
\hline & (0.91 to 1.19$)$ & (0.97 to 1.34$)$ & (1.10 to 1.32$)$ & (0.92 to 1.11$)$ \\
\hline \multicolumn{5}{|l|}{ Primary medical diagnosis } \\
\hline \multirow[t]{2}{*}{ Cancer } & 0.89 & 0.49 & 0.74 & 0.85 \\
\hline & (0.52 to 1.55$)$ & $(0.20$ to 1.20$)$ & $(0.43$ to 1.26$)$ & (0.48 to 1.49$)$ \\
\hline \multirow[t]{2}{*}{ Respiratory or digestive disease } & 0.38 * & 0.76 & 0.57 & 0.57 \\
\hline & (0.19 to 0.75$)$ & (0.36 to 1.61$)$ & (0.32 to 1.02$)$ & (0.31 to 1.04$)$ \\
\hline \multirow[t]{2}{*}{ Symptom or injury } & 0.59 & 1.35 & 1.07 & 0.40 * \\
\hline & (0.29 to 1.19$)$ & (0.64 to 2.87$)$ & $(0.63$ to 1.81$)$ & $(0.22$ to 0.73$)$ \\
\hline \multirow[t]{2}{*}{ Cardiovascular disease } & 0.82 & 0.70 & 0.94 & 1.22 \\
\hline & (0.36 to 1.86$)$ & $(0.23$ to 2.16$)$ & (0.49 to 1.83 ) & (0.67 to 2.24$)$ \\
\hline \multirow[t]{2}{*}{ Infectious disease } & 0.39 & 1.37 & 0.92 & 0.97 \\
\hline & (0.05 to 2.89$)$ & (0.31 to 6.02$)$ & (0.28 to 3.07$)$ & (0.32 to 2.67$)$ \\
\hline \multirow[t]{2}{*}{ Neurologic disease } & 1.33 & 4.51 * & 2.07 & 1.49 \\
\hline & (0.31 to 5.73 ) & (1.47 to 13.82$)$ & (0.87 to 4.90$)$ & (0.52 to 4.24$)$ \\
\hline Other $^{\dagger}$ & 1 [Reference] & 1 [Reference] & 1 [Reference] & 1 [Reference] \\
\hline \multicolumn{5}{|c|}{ Data are adjusted odds ratio ( $95 \%$ confidence interval) } \\
\hline \multicolumn{5}{|c|}{${ }^{\dagger}$ Includes genitourinary, musculoskeletal, eye, ear, and skin diseases } \\
\hline
\end{tabular}

\subsection{Secondary Outcomes: Injury Rates and Process Indicators}

During the intervention periods, the mean injury rates did not show significant intergroup differences $(0.42$ vs. $0.31, t=-1.54, P=0.1306)$. In the GLS analysis and fixed effect model, no significance was observed $(z=1.69, P=0.0911$ and $t=1.65, P=0.1049$, respectively).

Both the fall risk and injury risk factors were assessed within 24 hours of hospital admission in all patients in the intervention group, while no data available for process indicators in risk assessments for about 75\% HD in the control group. (Table 4) Universal precautions and education for at-risk HD were provided to most patients in the control group consistantly. The communication, and environmental interventions showed better practice in the control groups by 18 months, however, communication and environmental interventions of the intervention group increased up to the level of control group. While the rate of risktargeted interventions increased incrementally in both groups, the intervention group showed better adherence than the control group at the last period. (29.5\% vs. $18.1 \%, P<.0001)$ 
Table 4

Changes in process indicators in the two groups over time

\begin{tabular}{|c|c|c|c|c|c|c|}
\hline \multirow[t]{2}{*}{ Item } & & \multirow{2}{*}{$\begin{array}{l}\text { Baseline } \\
\text { Int. vs. } \\
\text { Cnt. }\end{array}$} & \multirow{2}{*}{$\begin{array}{l}\text { 1st period } \\
\text { Int. vs. } \\
\text { Cnt. }\end{array}$} & 2nd period & \multirow{2}{*}{$\begin{array}{c}\begin{array}{c}\text { 3rd } \\
\text { period }\end{array} \\
\text { Int. vs. Cnt. }\end{array}$} & \multirow{2}{*}{$\begin{array}{l}\text { 4th } \\
\text { period } \\
\text { Int. vs. } \\
\text { Cnt. }\end{array}$} \\
\hline & & & & Int. vs. Cnt. & & \\
\hline \multirow[t]{3}{*}{ Base data } & Hospital days (HD) & $\begin{array}{l}8254,4 \\
207\end{array}$ & $\begin{array}{l}45133 \\
31675\end{array}$ & $46403,39,733$ & $\begin{array}{l}44418,44 \\
741\end{array}$ & $\begin{array}{l}42553 \\
43161\end{array}$ \\
\hline & $\begin{array}{l}\text { Days on which no risk } \\
\text { assessment performed, \% }\end{array}$ & $\begin{array}{l}\text { 72.5, } \\
73.4^{\text {ns }}\end{array}$ & $0,72.6^{\star \star}$ & $0,77.1^{\star *}$ & $0,71.7^{\star *}$ & $0,79.8^{* *}$ \\
\hline & At-risk days relative to $\mathrm{HD}, \%$ & $\begin{array}{l}\text { 43.0, } \\
42.1^{\mathrm{ns}}\end{array}$ & $\begin{array}{l}24.5 \\
43.5^{\star *}\end{array}$ & $31.4,38.6^{* *}$ & $32.7,42.9^{\star *}$ & $\begin{array}{l}34.6 \\
41.5^{\star *}\end{array}$ \\
\hline \multirow[t]{8}{*}{$\begin{array}{l}\text { Process } \\
\text { indicator }\end{array}$} & $\begin{array}{l}\text { Patients assessed using a fall-risk tool within } 24 \text { hours of hospital } \\
\text { admission, \% }\end{array}$ & $\begin{array}{l}99.3 \\
98.6^{\mathrm{ns}}\end{array}$ & $\begin{array}{l}100.0^{\ddagger} \\
99.2^{\star \star}\end{array}$ & $100.0^{\ddagger}, 70.8^{\star \star}$ & $100.0^{\ddagger}, 95.3^{\star \star}$ & $\begin{array}{l}100.0^{\ddagger} \\
98.8^{\star \star}\end{array}$ \\
\hline & $\begin{array}{l}\text { Patients assessed for injury-risk factors }\left(\mathrm{ABCs}^{\dagger}\right) \text { within } 24 \text { hours } \\
\text { of hospital admission, \% }\end{array}$ & $0,0^{\mathrm{ns}}$ & $\begin{array}{l}100.0^{\ddagger} \\
0^{* \star}\end{array}$ & $100.0^{\ddagger}, 0^{\star *}$ & $100.0^{\ddagger}, 0^{\star *}$ & $\begin{array}{l}100.0^{\ddagger} \\
0^{* *}\end{array}$ \\
\hline & $\begin{array}{l}\text { Patients with additional nursing assessments of risk factors within } \\
24 \text { hours of hospital admission, \% }\end{array}$ & $\begin{array}{l}94.3 \\
98.6^{*}\end{array}$ & $\begin{array}{l}95.7 \\
99.7^{\star \star}\end{array}$ & $98.9,91.7^{* *}$ & $99.9,99.8^{\star *}$ & $\begin{array}{l}99.8 \\
99.6^{*}\end{array}$ \\
\hline & $\begin{array}{l}\text { At-risk patients to which universal precautions were applied within } \\
24 \text { hours of risk identification, \% }\end{array}$ & \multirow[t]{2}{*}{$\begin{array}{l}86.1 \S \\
100 . \S^{\star \star}\end{array}$} & \multirow[t]{2}{*}{$\begin{array}{l}69.7 \S \\
78.9 \S^{\star *}\end{array}$} & \multirow[t]{2}{*}{$88.8 \S, 99.9 \S^{\star \star}$} & $37.8,99.9^{\star *}$ & $\begin{array}{l}91.2 \\
99.9^{* *}\end{array}$ \\
\hline & $\begin{array}{l}\text { At-risk patients who received education interventions within } \\
24 \text { hours of risk identification, \% }\end{array}$ & & & & $33.1,98.1^{\star *}$ & $\begin{array}{l}\text { 79.6, } \\
97.8^{\star *}\end{array}$ \\
\hline & $\begin{array}{l}\text { At-risk patients who received risk-targeted interventions within } \\
24 \text { hours of risk identification, \% }\end{array}$ & $\begin{array}{l}<0.01,< \\
0.01^{\mathrm{ns}}\end{array}$ & $\begin{array}{l}<0.01,< \\
0.01^{\mathrm{ns}}\end{array}$ & $<0.01,<0.01^{\mathrm{ns}}$ & $12.5,13.3^{\mathrm{ns}}$ & $\begin{array}{l}29.5 \\
18.1^{\text {** }}\end{array}$ \\
\hline & $\begin{array}{l}\text { At-risk patients who received communication interventions within } \\
24 \text { hours of risk identification, \% }\end{array}$ & \multirow[t]{2}{*}{$\begin{array}{l}61.7 \S \\
79.4 \S^{\star \star}\end{array}$} & \multirow[t]{2}{*}{$\begin{array}{l}87.6 \S \\
99.9 \S^{\star *}\end{array}$} & \multirow[t]{2}{*}{$76.0 \S, 81.1 \S^{\star \star}$} & $30.2,38.7^{\star \star}$ & $\begin{array}{l}66.2 \\
66.7^{\mathrm{ns}}\end{array}$ \\
\hline & $\begin{array}{l}\text { At-risk patients who received environmental interventions within } \\
24 \text { hours of risk identification, \% }\end{array}$ & & & & $39.5,54.9^{\star *}$ & $\begin{array}{l}76.7 \\
76.0^{\text {ns }}\end{array}$ \\
\hline \multicolumn{7}{|c|}{ Int. and Cnt. stands for intervention group and control group } \\
\hline \multicolumn{7}{|c|}{${ }^{\dagger}$ stands for age, bone health, anti-coagulants, and current surgery } \\
\hline \multicolumn{7}{|c|}{ ‡ Function that was performed automatically by the analytic tool for predicting the fall risk } \\
\hline \multicolumn{7}{|c|}{$\S$ Data collection was not categorized in detail, } \\
\hline \multicolumn{7}{|c|}{ ns Not significant, ${ }^{*}<.05,{ }^{* *}<.0001$} \\
\hline
\end{tabular}

When we looked at the changes in frequency of nursing activities, the assessment in the intervention group increased from 1.05 at baseline to 49.926 months later. (Fig. 4) There was a slight increase from 9.85 at baseline to 12.95 during the same period in the control group. However, the trends reversed during the last period, with the values in the two groups becoming closer. The interventions provided to patients was markedly different between the two groups at baseline. It increased continuously in intervention group as well as control group.

\section{Discussion}

The introduction of a patient-level electronic analytic tool reduced the rates of falls, but the margin was small with notable differences in patient characteristics between the two groups. The analytic tool approach was feasible and acceptable to nurses and contributed to the completion of fall-risk assessments and to improvement of process outcomes for risk-targeted interventions recommended by clinical guidelines. It had no effect on rates of fallrelated injuries compared with usual care. Considering the limitations of a single site approach, these results imply that the electronic fall-predictive analytic tool may have potential to help nurses make informed clinical decisions and manage care time efficiently about prioritizing to whom and what intervention should be planned and conducted.

Several factors need to be considered given the mixed results for the outcomes of this study. The first one is related to the underreporting rates of falls which were considered common for adverse events and observed 3 years ago among several units at the site $(33,34)$. This might affect the results of interrupted time series analysis by underestimating the rates of falls at the pre-intervention periods which led to dilute intervention effects. During the study period, the underreporting rates ranged $15 \sim 20 \%$ for both groups. The second factor to consider is the introduction of a new documentation screen in the EHR system to both groups. This new screen was a list of care plan interventions organized by risk factors and it might also have affected fall prevention practices in the control group. Even though it was a static screen, not tailored to patient-level, it may have served as a reminder of guidelines to nurses and increased appropriate preventative interventions which also contributed to dilution of this study's intervention effects. 
The third factor is two unexpected occurrences at the hospital. One month after study initiation, one nursing unit in each group moved to a new location and nurse staffing was reorganized due to physical reconstruction of the hospital buildings. The fall rate increased markedly for several months in the intervention unit compared to the other five units in the group. However, the control group unit showed only slight changes compared to those in the other units. The relocations were accompanied by changes in staff nurses and the patients' medical diagnoses, which might have increased the burden on nurses and induced the sudden increase in the fall rate at the unit. The other occurrence was the mandatory routinization of hourly nursing rounds to all inpatients by the policy of the hospital's safety committee during the last 6-month period, which may account for the sudden increase of nursing assessments in the control group.

These factors imply that there were strong contamination and confounding during this experiment, which might lead to some differences between the two groups for fall rates. The nature of low prevalence of inpatient falls of about 2.0 per $1000 \mathrm{HD}$ and single site approach required long term period of time and we were unable to control for some contamination and confounding. One previous cluster randomized controlled trial (RCT) intervention study (36) showed a significant intervention effect over the 6-month intervention period and reported 3.15 and 4.18 rates of falls in the intervention and control units respectively. Another cluster RCT conducted over a 12-month period in Australia reported a fall prevalence of 3.05. One current US intervention study (37) reported 6-month intervention period with 2.80 prevalence. Compared to these studies, the study site had the lowest prevalence and longest intervention period.

Despite the contamination and confounding, some improvement in the primary outcome was observed. This result suggests that a multi-site RCT in needed in the future to provide more rigorous evidence. In addition, if the intervention is combined with dynamic decision support features in an EHR system such as guiding intervention tailored to patient-level specific risk factors, we could expect additional improvement (37).

As for the nurses' behaviors on the intervention units, we saw rapid improvement in nursing assessments in the intervention group in the first period of the study in contrast with limited improvement with the control group despite similar levels at baseline. The participating nurses commented that they payed additional attention to assessment because of concerns that the IN@SIGHT might miscalculate the probability of falls due to lack of data (30). This finding can be understood by the nonadoption, abandonment, scale-up, spread, and sustainability (NASSS) framework (38) illuminating the success or failure of technology-supported health or social care programs. The framework's domain of adopter system (e.g., staff and nurses) often do not engage with a program or use the technology due to concerns about threats to their scope of practice or to the safety and welfare of the patient, which leads to first gathering additional information on risks. A qualitative exploration study (20) reported similar findings when investigating how nurses perceive predictive information and how they act on it. The study reported that nurses attempted to gather more information from additional sources during uncertainty and desired to review more detailed information underlying predictions. Considering that predictive information is relatively new to nurses, these changes are positive and desirable in terms of both quality of care and quality of data in EHRs.

With regard to the process indicators, the results showed that the IN@SIGHT intervention improved the completeness of risk assessment and injury-risk factor assessment. However, the control unit nurses used to provide universal fall precautions more consistently to patients than nurses on the intervention units. In fall prevention, universal fall precautions should be provided to all inpatients to prevent accidental falls. Considering that accidental falls are responsible for about $14 \%$ of inpatient falls (39), the control group was more likely to show better patient outcomes. The multifactor interventions of education, communication, and environment were also delivered more frequently to at-risk patients of the control group. These findings imply that the control group practice was better than the intervention group from the baseline and the analytic tool did not affect universal fall precaution care. While, as for the risktargeted interventions, the intervention group showed slow, better improvement than the control group, and the difference became significant in the last time period. This finding is meaningful considering that risk-targeted interventions prevent anticipated physiologic falls which are responsible for up over $70 \%$ of inpatient falls $(34,39)$.

The design of this study had several limitations. First, the implementation at a single site for long study period introduced a lot of confounding and limited the generalizability of the study findings. To control for hospital-level structural variables, we selected control units according to similar characteristics of the patients, but there were still some important differences. We compared the underlying trends using an interrupted time series and adjusted for patient-level risks, but patient differences on control and intervention units may have affected the study findings. Second, we were unable to compare the change in injury fall rate trends at pre- and post-intervention periods. Third, other quality initiatives may have been implemented at the hospital during the study period that affected both the nurse throughput and the appropriate use of care resources.

Despite these limitations, this study has a strong point which may be considerable for future outcome studies. We traced and monitored the changes of relevant nursing activities provided to patients with process measures over time. Using the measures, we could witness the slow, but explicit qualitative changes in nursing interventions of the intervention group rather than quantitative changes, which indicates that the processes underlying care elements have improved, and improvements in patient outcomes would follow (40). The continuous measurement and analysis of process outcomes were informative to infer the effect of interventions to patient outcomes as well as interpret the effect of confounding, which had been rarely taken into account at existing studies $(7,36,41)$. This study's approach and methods suggested what process outcomes and how those could be measured, reported, and interpreted.

\section{Conclusions}

Our new electronic analytic tool for predicting inpatient fall risk demonstrated the potential to contribute to reducing the fall rate among hospitalized patients and leading to positive, qualitative changes in process outcomes. Nurses were amenable to using the tool, and hospital managers used the tool to make informed decisions aimed at preventing falls. As an example of nursing predictive analytics application, defined as the use of electronic algorithms that forecast patient events in near-real time and point-of-care to improve outcomes and reduce costs, this study showed how we can use available EHR data to improve nursing sensitive outcomes. The efficacy of the tool could be maximized by combining it with efficient, tailored interventions for preventing falls as well as continuously updating it according to changes in user behaviors. 


\section{Declarations}

\section{Ethical approval and consent to participate:}

The authors got waive the need to obtain consent from individual patients and nurse from the IRB of National Health Insurance Service llsan Hospital (IRB No. NHIMC 2016-08-005)

Consent for publication: Not applicable

\section{Competing interests: None}

Funding: This study was supported by a grants from the Korea Healthcare Technology R\&D Project, Ministry for Health and Welfare (No. HI17C0807), the National Research Foundation of Korea (No. NRF-2019R1A2C2007583), and the Ministry of Trade, Industry and Energy of Korea (No. 20004861)

\section{Data Sharing Statement:}

The data that support the findings of this study are available from the National Health Insurance Service Ilsan Hospital, but restrictions apply to the availability of these data, which were used under license for the current study, and so are not publicly available. Data are however available from the authors upon reasonable request and with permission of National Health Insurance Service Ilsan Hospital.

\section{Authors' contributions:}

I. C. conceived and designed the study, supervised and contributed to the data analysis, interpreted results, and drafted and revised the paper. I. J. and H.P. contributed to study design, data acquisition, and data analysis. PC. D. provided substantial contribution to the interpretation of data analysis and revised the work critically for important intellectual content.

\section{Acknowledgements:}

We thank to Cheehang Kim and Jisun Cho of the Nursing Department, and Yunjeong Choi of the Medical Information Department at Ilsan hospital for helping us to conduct this study administratively and technically. We also appreciate all the clinical staffs of the Nursing Department and graduate students involved in data collection, review and analysis.

\section{References}

1. Spetz J, Brown DS, Aydin C. The economics of preventing hospital falls: demonstrating ROI through a simple model. J Nurs Admin. 2015;45(1):50-7.

2. Wong CA, Recktenwald AJ, Jones ML, Waterman BM, Bollini ML, Dunagan WC. The cost of serious fall-related injuries at three Midwestern hospitals. Jt Comm J Qual Patient Saf. 2011;37(2):81-7.

3. Lee E-S, Ahn M-J, Kim Y-M, Jo I-J, Jang D-E, Development and effects of fall prevention model: Safety for utilizing medical big data based artificial intelligence. Proceeding of Korean Society of Medical Informatics; 2018 Fall November, 23-24; Jeonju-si, Korea.

4. Cho MS, Lee HY. Factors Associated with Injuries after Inpatient Falls in a Tertiary Hospital. J Korean Clin Nurs Res. 2017;23(2):202-10. https://doi.org/10.22650/JKCNR.2017.23.2.202.

5. Lee JY, Jin Y, Piao J, Lee S-M. Development and evaluation of an automated fall risk assessment system. Int J Qual Health Care. 2016;28(2):175-82.

6. Lopez KD, Gerling GJ, Cary MP, Kanak MF. Cognitive work analysis to evaluate the problem of patient falls in an inpatient setting. J Am Med Inform Assoc. 2010;17(3):313-21.

7. Barker AL, Morello RT, Wolfe R, Brand CA, Haines TP, Hill KD, et al. 6-PACK programme to decrease fall injuries in acute hospitals: cluster randomised controlled trial. BMJ. 2016;352:h6781. https://doi.org/10.1136/bmj.h6781.

8. The Joint Commission. Sentinel event alert 55: Preventing falls and fall-related injuries in health care facilities. Sentinel Event Alert. 2015. http://www jointcommission org/assets/1/18/SEA_55 pdf. Accessed 28 Sept 2018. PMID: 26422837.

9. Centre for Clinical Practice at NICE (UK). Falls in older people: assessing risk and prevention. London: National Institute for Health and Care Excellence (UK): National Institute for Health and Care Excellence; 2013. https://www.ncbi.nIm.nih.gov/books/NBK258885/pdf/Bookshelf_NBK258885.pdf. Accessed 8 Aug 2018.

10. Aranda-Gallardo M, Morales-Asencio JM, Canca-Sanchez JC, Barrero-Sojo S, Perez-Jimenez C, Morales-Fernandez A, et al. Instruments for assessing the risk of falls in acute hospitalized patients: a systematic review and meta-analysis. BMC Health Serv Res. 2013;13(1):122. https://doi.org/10.1186/14726963-13-122.

11. Park S-H, Kim E-K. Systematic review and meta-analysis for usefulness of fall risk assessment tools in adult inpatients. Korean $\mathrm{J}$ Health Promot. 2016;16(3):180-91. https://doi.org/10.15384/kjhp.2016.16.3.180.

12. Registered Nurses' Association of Ontario (RNAO). Preventing Falls and Reducing Injury from Falls (4th ed.). Ontarion, Canada 2017. https://rnao.ca/sites/rnao-ca/files/bpg/FALL_PREVENTION_WEB_1207-17.pdf. Accessed 8 Aug 2018.

13. Jeffery AD. Methodological challenges in examining the impact of healthcare predictive analytics on nursing-sensitive patient outcomes. Comput Inform Nurs. 2015;33(6):258-64. doi:10.1097/CIN.0000000000000154.

14. Cho I, Boo E-H, Chung E, Bates DW, Dykes P. Novel Approach to Inpatient Fall Risk Prediction and Its Cross-Site Validation Using Time-Variant Data. J Med Internet Res. 2019;21(2):e11505. doi:10.2196/11505. 
15. Austrian JS, Jamin CT, Doty GR, Blecker S. Impact of an emergency department electronic sepsis surveillance system on patient mortality and length of stay. J Am Med Inform Assoc. 2017;25(5):523-9. doi:10.1093/jamia/ocx072.

16. Bailey TC, Chen Y, Mao Y, Lu C, Hackmann G, Micek ST, et al. A trial of a real-time Alert for clinical deterioration in Patients hospitalized on general medical wards. J Hosp Med. 2013;8(5):236-42. doi:10.1002/jhm.2009.

17. Cho I, Park I, Kim E, Lee E, Bates DW. Using EHR data to predict hospital-acquired pressure ulcers: a prospective study of a Bayesian Network model. Int J Med Inform. 2013;82(11):1059-67. doi:10.1016/j.jimedinf.2013.06.012.

18. Kollef MH, Chen Y, Heard K, LaRossa GN, Lu C, Martin NR, et al. A randomized trial of real-time automated clinical deterioration alerts sent to a rapid response team. J Hosp Med. 2014;9(7):424-9. https://doi.org/10.1002/jhm.2193.

19. Sawyer AM, Deal EN, Labelle AJ, Witt C, Thiel SW, Heard K, et al. Implementation of a real-time computerized sepsis alert in nonintensive care unit patients. Crit Care Med. 2011;39(3):469-73. doi:10.1097/CCM.0b013e318205df85.

20. Jeffery AD, Kennedy B, Dietrich MS, Mion LC, Novak LL. A Qualitative exploration of nurses' information-gathering behaviors prior to decision support tool design. Appl Clin Inform. 2017;8(03):763-78. doi:10.4338/ACI-2017-02-RA-0033.

21. Honeyford K, Cooke GS, Kinderlerer A, Williamson E, Gilchrist M, Holmes A, et al. Evaluating a digital sepsis alert in a London multisite hospital network: a natural experiment using electronic health record data. J Am Med Inform Assoc. 2020;27(2):274-83. https://doi.org/10.1093/jamia/ocz186.

22. Parikh RB, Kakad M, Bates DW. Integrating predictive analytics into high-value care: the dawn of precision delivery. JAMA. 2016;315(7):651-2.

23. Registered Nurses'Association of Ontario (RNAO) \& Canadian Patient Safety Institute (CPSI). Reducing Falls and Injuries from Falls Getting Started Kit: Evidence Update. 2015.

http://www.patientsafetyinstitute.ca/en/toolsResources/Documents/Interventions/Reducing\%20Falls\%20and\%20Injury\%20from\%20Falls/Falls\%20Evidel 01.PDF. Accessed 8 Aug 2018.

24. Ganz D, Huang C, Saliba D, Miake-Lye I, Hempel S, Ensrud K. Preventing falls in hospitals: a toolkit for improving quality of care. Ann Intern Med. 2013;158(5 Pt 2):390-6.

25. Vreeman DJ, McDonald CJ, Huff SM. LOINC@: a universal catalogue of individual clinical observations and uniform representation of enumerated collections. Int J Funct Inform Personal Med. 2010;3(4):273-91. doi:10.1504/IJFIPM.2010.040211.

26. World Health Organization. Classifications: International Classification for Nursing Practice (ICNP). 2018. http://www.who.int/classifications/icd/adaptations/icnp/en/. Accessed 3 Sep 2018.

27. Hendrich A. How to try this: predicting patient falls. Using the Hendrich II Fall Risk Model in clinical practice. Am J Nurs. 2007;107(11):50-8. doi:10.1097/01.NAJ.0000298062.27349.8e.

28. Oliver D, Britton M, Seed P, Martin F, Hopper A. Development and evaluation of evidence based risk assessment tool (STRATIFY) to predict which elderly inpatients will fall: case-control and cohort studies. BMJ. 1997;315(25):1049-53. doi:10.1136/bmj.315.7115.1049.

29. Irvine D, Sidani S, Hall LM. Linking outcomes to nurses' roles in health care. Nurs Econ. 1998;16(2):58. doi:10.1504/IJFIPM.2010.040211.

30. Cho I, Jin I. Responses of Staff Nurses to an EMR-Based Clinical Decision Support Service for Predicting Inpatient Fall Risk. Stud Health Technol Inform. 2019;264:1650-1. doi:10.3233/shti190579.

31. American Nurses Association. Guidelines for data collection on the American Nurses Association's national quality forum endorsed measures: Nursing care hours per patient day; skill-mix; falls; falls with injury. Kansas City: KU School of Nursing; 2012.

32. Cho I, Kim J, Chae J, Jung M, Kim Y. Development of ICNP-based inpatient falls prevention catalogue. Int Nurs Rev. 2019. https://doi.org/10.1111/inr.12566.

33. Cho I, Boo E-H, Lee S-Y, Dykes PC. Automatic population of eMeasurements from EHR systems for inpatient falls. J Am Med Inform Assoc. 2018;25(6):730-8. doi:10.1093/jamia/ocy018.

34. Hill AM, Hoffmann T, Hill K, Oliver D, Beer C, McPhail S, et al. Measuring falls events in acute hospitals-a comparison of three reporting methods to identify missing data in the hospital reporting system. J Am Geriatr Soc. 2010;58(7):1347-52. doi:10.1111/j.1532-5415.2010.02856.x.

35. Bernal JL, Cummins S, Gasparrini A. Interrupted time series regression for the evaluation of public health interventions: a tutorial. Int J Epidemiol. 2017;46(1):348-55. doi:10.1093/ije/dyw098.

36. Dykes PC, Carroll DL, Hurley A, Lipsitz S, Benoit A, Chang F, et al. Fall prevention in acute care hospitals: a randomized trial. JAMA. 2010;304(17):1912-8. doi:10.1001/jama.2010.1567.

37. Dykes PC, Duckworth M, Cunningham S, Dubois S, Driscoll M, Feliciano Z, et al. Pilot testing fall TIPS (Tailoring Interventions for Patient Safety): a patient-centered fall prevention toolkit. Jt Comm J Qual Patient Saf. 2017;43(8):403-13.

38. Greenhalgh T, Wherton J, Papoutsi C, Lynch J, Hughes G, Hinder S, et al. Beyond adoption: a new framework for theorizing and evaluating nonadoption, abandonment, and challenges to the scale-up, spread, and sustainability of health and care technologies. J Med Internet Res. 2017;19(11):e367. doi:10.2196/jmir.8775.

39. Oliver D, Healey F, Haines TP. Preventing falls and fall-related injuries in hospitals. Clin Geriatr Med. 2010;26(4):645-92. doi:10.1016/j.cger.2010.06.005.

40. Mant J. Process versus outcome indicators in the assessment of quality of health care. International J Qual Health Care. 2001;13(6):475-80.

41. Cumming RG, Sherrington C, Lord SR, Simpson JM, Vogler C, Cameron ID, et al. Cluster randomised trial of a targeted multifactorial intervention to prevent falls among older people in hospital. BMJ. 2008;336(7647):758-60.

\section{Figures}




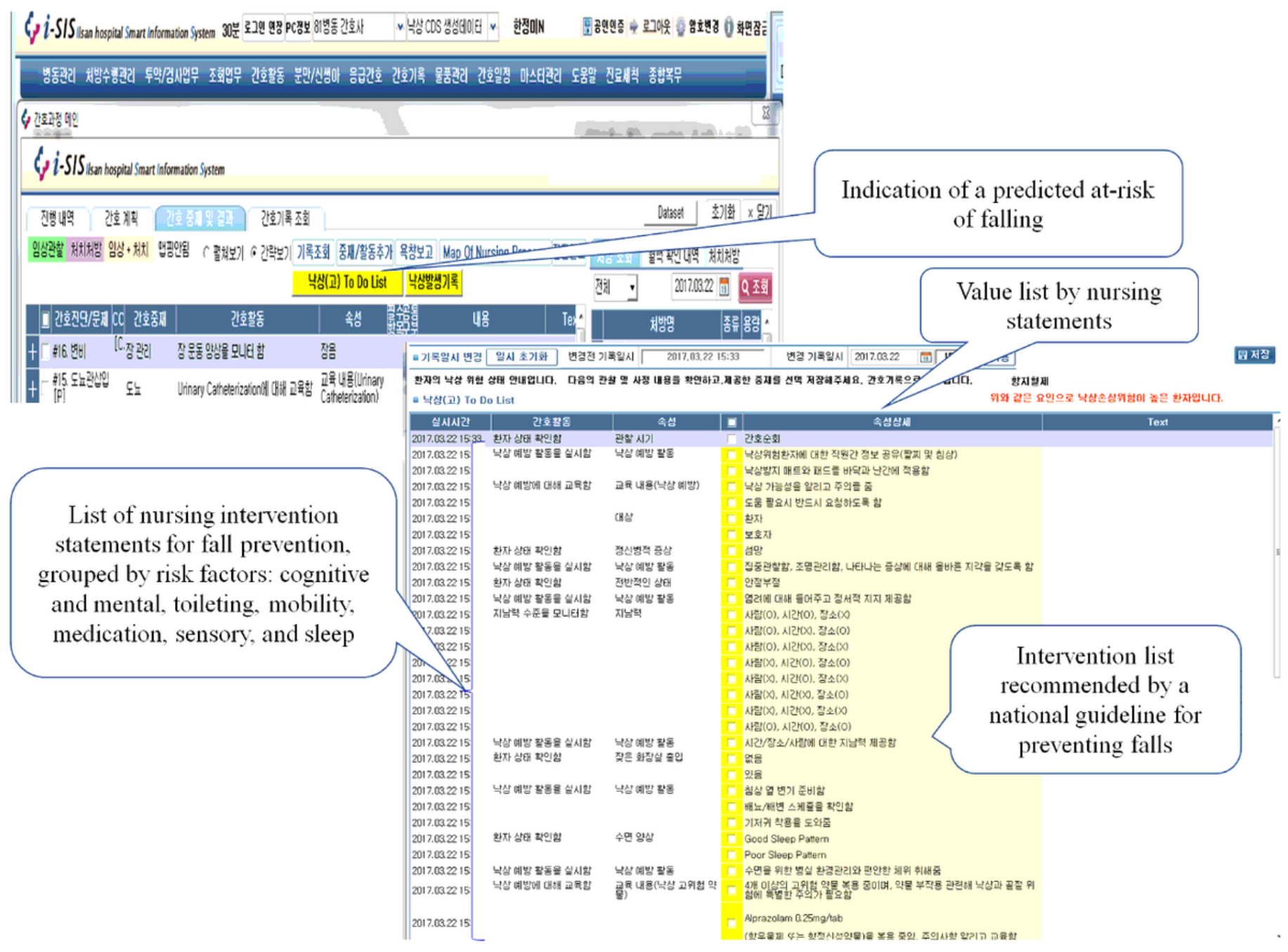

Figure 1

Screenshots of an electronic nursing record showing (1) how a high risk of falling as predicted by the IN@SIGHT analytic tool is displayed and (2) the nursing record screen when selecting 'At-risk fall: To do list (fall prevention interventions)'

\section{USUAL CARE}

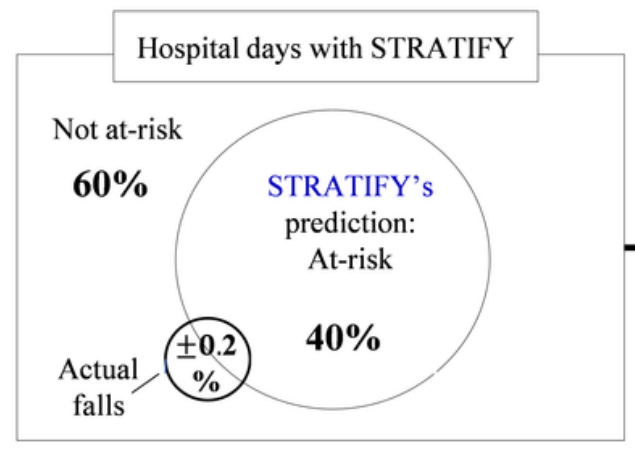

\section{USE OF ANALYTIC TOOL (IN@SIGHT)}

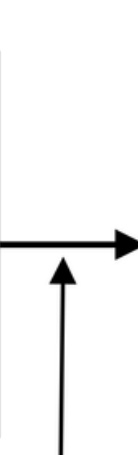

Intervention of the

IN@SIGHT

with higher sensitivity

than the STRATIFY, given the similar specificity
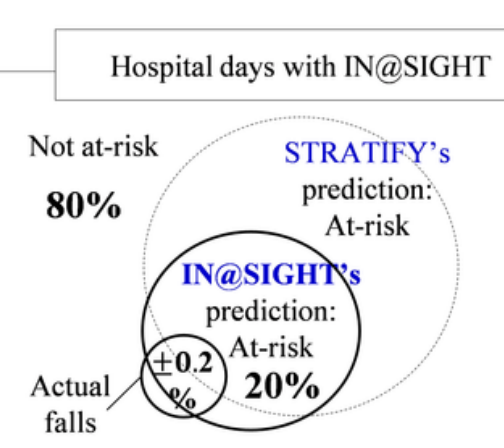

falls

\section{OUTCOMES}

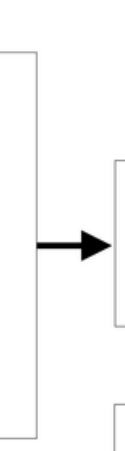

Increase of risk-targeted interventions maintaining universal interventions

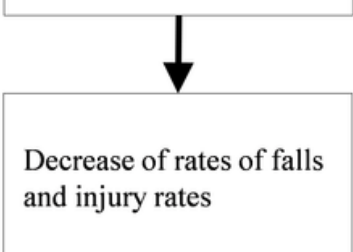

\section{Figure 2}




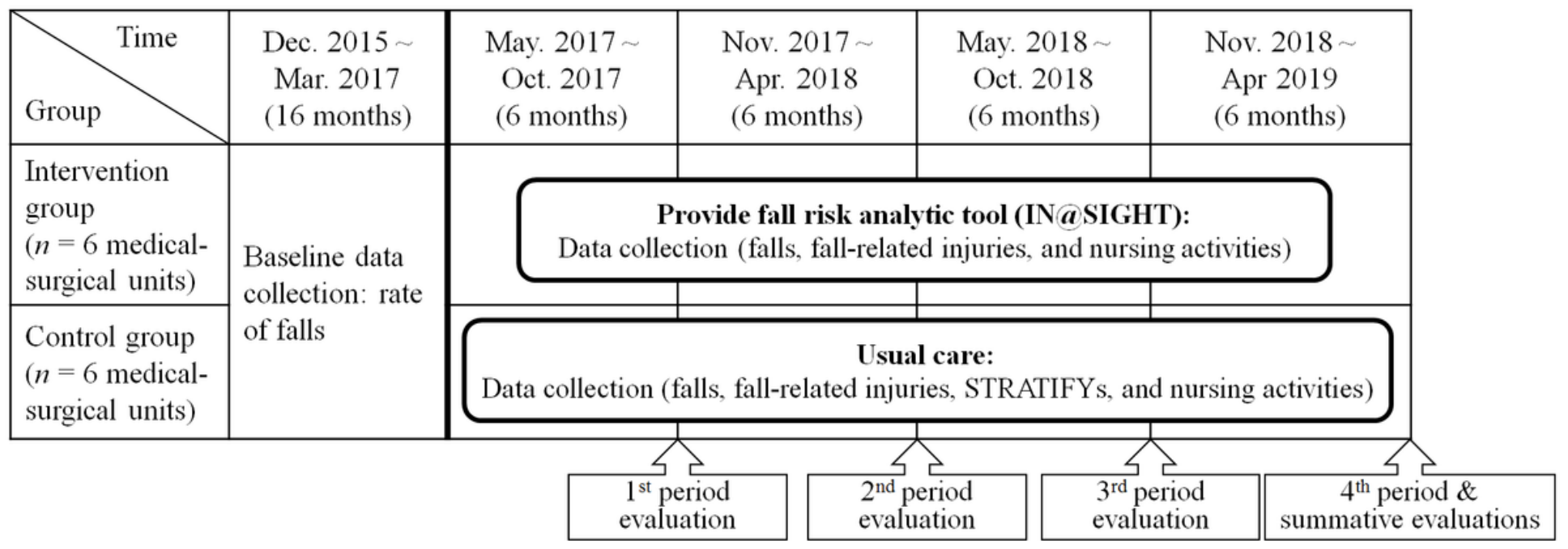

Figure 3

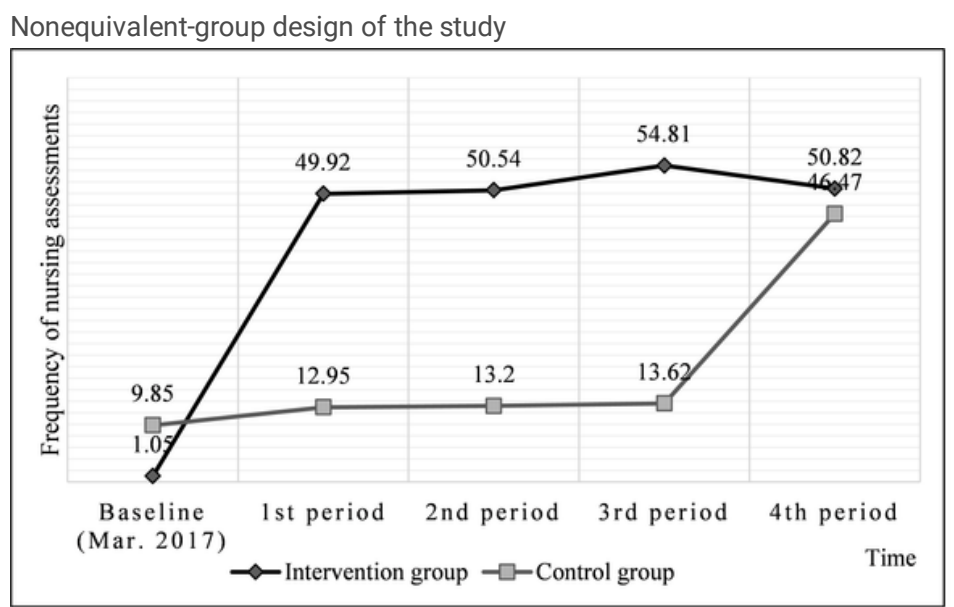

(A) Nursing assessments

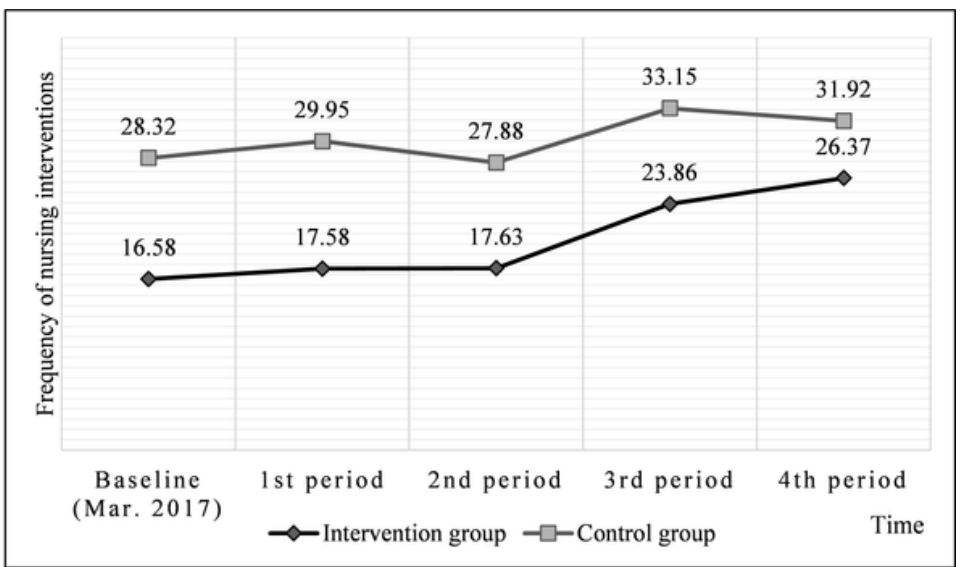

(B) Nursing interventions

Figure 4

Changes in frequency of nursing activities by 6 months and group

\section{Supplementary Files}

This is a list of supplementary files associated with this preprint. Click to download.

- TIDieRChecklistlmpactFallPredivtion.docx

- TIDieRChecklistlmpactFallPredivtion.docx

- TIDieRChecklistImpactFallPredivtion.docx 